\title{
PRODUÇÃo DE GÁS DE SÍNTESE POR PLASMA TÉRMICO VIA PIRÓLISE DE METANO E DIÓXIDO DE CARBONO
}

Péricles Inácio Khalaf

Departamento de Química, Universidade Tecnológica Federal do Paraná, 85503-390 Pato Branco - PR, Brasil

Ivan Gonçalves de Souza, Eduardo Carasek e Nito Angelo Debacher*

Departamento de Química, Universidade Federal de Santa Catarina, 88040-900 Florianópolis - SC, Brasil

Recebido em 28/8/10; aceito em 5/5/11; publicado na web em 8/7/11

PRODUCTION OF SYNTHESIS GAS BY THERMAL PLASMA VIA PYROLYSIS OF METHANE AND CARBON DIOXIDE. In this work the production of synthesis gas from a mixture of methane $\left(\mathrm{CH}_{4}\right)$ and carbon dioxide $\left(\mathrm{CO}_{2}\right)$ by thermal plasma was studied. The best relation found for the gas mixture $\left[\mathrm{CO}_{2}\right] /\left[\mathrm{CH}_{4}\right]$ was 1.3. Under the excess of $\mathrm{CH}_{4}$ in the gas mixture soot was formed and also benzene, indene and naphthalene were identified. The disulfides compounds in the gas mixture were degraded causing no interference in the synthesis gas production, suggesting no needs of pretreatment step for sulfurorganic compounds removal in the process.

Keywords: synthesis gas; biogas; argon thermal plasma.

\section{INTRODUÇÃO}

O biogás é o produto da decomposição por micro-organismos em condições anaeróbicas de matéria orgânica proveniente de diferentes fontes, como aterros sanitários, biodigestores e resíduos animais. A composição do biogás varia de acordo com o tipo de matéria orgânica precursora sendo constituído principalmente de metano (45 a $65 \%$ ), dióxido de carbono (35 a 41\%), nitrogênio (1 a 17\%) e oxigênio (< $1 \%$ ). Contém também, em menor quantidade, outros compostos orgânicos, como benzeno e tolueno, aldeídos e cetonas, ácidos graxos voláteis, sulfetos e dissulfetos, amônia e aminas, conferindo ao biogás cheiro desagradável.

O biogás pode ser usado como combustível, devido à alta porcentagem de metano em sua composição, que pode chegar a $65 \%$ (v/v) em biodigestores de esgoto, ${ }^{1}$ e elevada entalpia de combustão do metano $\Delta_{\mathrm{c}} \mathrm{H}^{\mathrm{o}}=-890 \mathrm{~kJ} \mathrm{~mol}^{-1}{ }^{2}$ Também pode ser usado em processos de reforma catalítica ou reforma a seco na produção de gás de síntese (singás). No processo catalítico a presença de compostos sulfurados causa envenenamento do catalisador requerendo uma etapa de prétratamento dos gases. A reforma a seco permite a conversão de $\mathrm{CH}_{4}$ e $\mathrm{CO}_{2}$, em gás de síntese através das seguintes reações: Equação 1 , na razão de 1:1 entre $\mathrm{H}_{2} / \mathrm{CO}$; adequada para síntese de metanol (Equação 2) ou para o processo Fisher-Tropsch para a produção de alcanos (Equação 3): 3,4

$$
\begin{gathered}
\mathrm{CH}_{4(\mathrm{~g})}+\mathrm{CO}_{2(\mathrm{~g})} \rightarrow 2 \mathrm{H}_{2(\mathrm{~g})}+2 \mathrm{CO}_{(\mathrm{g})} \\
\mathrm{CO}_{(\mathrm{g})}+2 \mathrm{H}_{2(\mathrm{~g})} \rightarrow \mathrm{CH}_{3} \mathrm{OH}_{(l)} \\
(2 n+1) \mathrm{H}_{2(\mathrm{~g})}+n \mathrm{CO}_{(\mathrm{g})} \rightarrow \mathrm{C}_{n} \mathrm{H}_{(2 n+2)}+n \mathrm{H}_{2} \mathrm{O}_{(l)}
\end{gathered}
$$

A reforma é especialmente conveniente para gases provenientes de fontes que apresentem quantidades similares de $\mathrm{CH}_{4}$ e $\mathrm{CO}_{2}$, por exemplo, biogás de aterros. A reforma de metano com $\mathrm{CO}_{2}$ é acompanhada por reações competitivas paralelas (Equações 4, 5 e 6), que

*e-mail: debacher@qmc.ufsc.br modificam o equilíbrio de conversão do $\mathrm{CO}_{2}$ e $\mathrm{CH}_{4}$ : ${ }^{3,4}$

$$
\begin{gathered}
\mathrm{CO}_{2(\mathrm{~g})}+\mathrm{H}_{2(\mathrm{~g})} \rightarrow \mathrm{H}_{2} \mathrm{O}_{(\mathrm{g})}+\mathrm{CO}_{(\mathrm{g})} \\
2 \mathrm{CO}_{(\mathrm{g})} \rightarrow \mathrm{CO}_{2(\mathrm{~g})}+\mathrm{C}_{(\mathrm{s})} \\
\mathrm{CH}_{4(\mathrm{~g})} \rightarrow \mathrm{C}_{(\mathrm{s})}+2 \mathrm{H}_{2(\mathrm{~g})}
\end{gathered}
$$

A reação 4 aumenta a conversão de $\mathrm{CO}_{2}$ e o rendimento de $\mathrm{CO}$, a reação de Boudouard (Equação 5) diminui a conversão de $\mathrm{CO}_{2}$ e o rendimento de $\mathrm{CO}$; a Equação 6 aumenta a conversão do metano e o rendimento de $\mathrm{H}_{2}$. As reações 5 e 6 são também responsáveis pela formação de carbono sólido durante o processo. ${ }^{4}$

Os processos de reforma comumente usados na indústria possuem várias limitações técnicas, tais como ignição lenta, necessidade de uma fonte térmica externa devido ao elevado calor absorvido pela reação e a remoção de compostos sulfurados para evitar o envenenamento do catalisador. ${ }^{5-8}$

Para superar as limitações das técnicas tradicionais, novas propostas de reforma estão sendo estudadas como, por exemplo, a reforma por plasma térmico. O plasma térmico consiste de uma mistura de espécies quimicamente ativas altamente energéticas formadas de partículas neutras, íons, fótons e elétrons em equilíbrio termodinâmico, em que as temperaturas do elétron e das partículas estão em equilíbrio na faixa de 3.000 a $50.000 \mathrm{~K} .{ }^{9}$ Na reação de reforma do biogás por plasma térmico, a alta temperatura do meio e todas estas espécies ativa participam na quebra das ligações químicas para produzir novas espécies.

A reforma via plasma térmico é uma alternativa promissora, pois a alta energia do plasma pode ser empregada para produzir espécies ionizadas altamente reativas em fase gasosa. ${ }^{9} \mathrm{O}$ processo de decomposição ou degradação de moléculas por plasma térmico segue duas etapas: na primeira, a alta temperatura gerada pelo gás ionizado (plasma) juntamente com a dissociação por impacto de elétrons quebram as ligações químicas das moléculas formando radicais livres extremamente reativos e instáveis que, na segunda etapa, no esfriamento da mistura gasosa, se recombinam espontaneamente formando novas substâncias. ${ }^{10,11}$ 
Tao et al. ${ }^{12}$ estudaram a reforma do metano usando uma mistura comercial de $\mathrm{CH}_{4}$ com $\mathrm{CO}_{2}$ por plasma térmico do tipo binodal (dois anodos) com o objetivo de reduzir o consumo de energia do processo e concluíram que, embora a seletividade fosse alta a eficiência energética de conversão usando este tipo de tocha foi baixa. Yan et al. ${ }^{12}$ estudaram a reforma a seco do metano usando uma mistura comercial de $\mathrm{CH}_{4}$ com $\mathrm{CO}_{2}$ na relação de 1:1, empregando dois tipos de tochas de plasma de corrente contínua - de arco e de pulso - e concluíram que a tocha de arco foi mais eficiente. No entanto, observaram que a relação de 1:1 produziu negro de carbono, o que é indesejável.

Os trabalhos encontrados na literatura sobre a reforma do metano por plasma térmico usam misturas gasosas comerciais como material de partida e são, em geral, voltados ao estudo do tipo de tocha de plasma térmico a ser empregada. A reforma do metano usando biogás como material de partida é mais estudada usando plasma frio. O plasma frio, ou plasma em não equilíbrio termodinâmico, ${ }^{9}$ é produzido à temperatura ambiente e, apesar de mais investigado para a reação de reforma do biogás, mostrou-se menos eficiente devido à baixa seletividade na conversão em gás de síntese.

Embora a tecnologia por plasma térmico aplicado à produção de gás de síntese pela reforma do biogás se mostre eficiente, vários aspectos do processo precisam ainda ser elucidados, tais como, composição e pureza do material de partida, proporção da mistura dos componentes e identificação das diferentes substâncias formadas. Desta forma, o objetivo do presente trabalho foi produzir gás de síntese por plasma térmico a partir da mistura $\mathrm{CH}_{4} / \mathrm{CO}_{2}$, em proporções variadas, simulando biogás e a identificação e caracterização dos produtos formados no processo. Também foram avaliados o efeito da composição da mistura do biogás $\mathrm{CH}_{4} / \mathrm{CO}_{2}$ na percentagem de conversão dos reagentes pelo método univariado ${ }^{13}$ e o efeito de contaminantes derivados de enxofre contidos na mistura gasosa na produção de reações secundárias no processo.

\section{PARTE EXPERIMENTAL}

A Figura 1 mostra um diagrama do equipamento usado, que consiste de: (1) cilindros de diversos gases, metano $\left(\mathrm{CH}_{4}\right)$, dióxido de carbono $\left(\mathrm{CO}_{2}\right)$ e argônio (Ar); (2) rotâmetros; (3) misturador de gases; (4) reator; (5) tocha de plasma; (6) fonte de corrente contínua (DC); (7) sistema de refrigeração através da circulação d'água, (8) analisador e amostrador de gases e (9) filtro de material particulado.

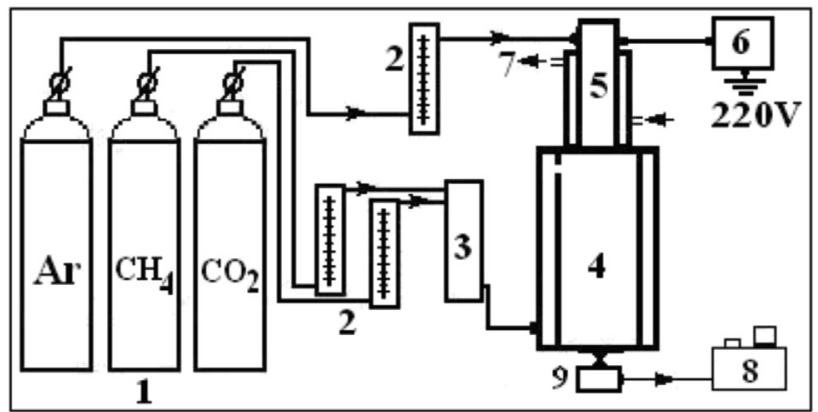

Figura 1. Esquema do equipamento usado na reforma por plasma térmico: (1) cilindros de gases; (2) rotâmetros; (3) misturador de gases; (4) reator; (5) tocha de plasma; (6) fonte de corrente contínua (DC); (7) sistema de refrigeração, (8) analisador e amostrador de gases e (9) filtro para reter material particulado

O equipamento foi desenvolvido no Laboratório de Tecnologia de Plasma do Departamento de Química da UFSC. ${ }^{11}$ A tocha de plasma (5) foi usada para produzir o jato de plasma ou gás ionizado através da aplicação de uma diferença de potencial entre os eletrodos com potência aplicada de até $4,5 \mathrm{~kW}$. Argônio comercial foi usado como gás plasmogênico em todos os experimentos com vazão de $15 \mathrm{~L}$ $\min ^{-1}$, controlada através do rotâmetro (2). A mistura de dióxido de carbono $\left(\mathrm{CO}_{2}\right)$ e metano $\left(\mathrm{CH}_{4}\right)$ foi injetada na entrada lateral inferior da câmara de plasma (4) após passar pelo rotâmetro (2) e misturador (3). Os produtos gasosos da reforma foram analisados através de um analisador de gases on-line e/ou coletados por amostradores (8) para posterior análise por GC-TCD. O material sólido formado no processo foi retido por filtros eletrostáticos (9).

Os gases usados para compor a mistura sintética de biogás foram metano e dióxido de carbono comercial.

Para avaliação do efeito da concentração do dióxido de carbono na conversão da mistura, a faixa de variação de concentração de $\mathrm{CO}_{2}$ foi de 3,2 a 14,0\%, mantendo-se a concentração de metano em 8,0\%. Para avaliação do efeito da concentração de metano na conversão da mistura, a faixa de concentração do metano foi de 4,0 a 12,0\%, mantendo-se a concentração de dióxido de carbono em 7,0\%.

A análise por GC-MS dos gases $\left(\mathrm{CO}_{2}\right.$ e $\left.\mathrm{CH}_{4}\right)$ foi feita antes da reação de reforma com o plasma desligado (somente com a passagem argônio) para comparação e após a reação de reforma para identificação das diferentes espécies produzidas. Para a pré-concentração dos analítos foi usada a técnica de microextração em fase sólida (SPME) empregando fibra de PDMS (polidimetilsiloxano) - Carbowax (Supelco $75 \mu \mathrm{m}$ de recobrimento). ${ }^{14}$ Para a coleta dos gases empregou-se um amostrador de gases com septo para inserção da agulha contendo o suporte da fibra de SPME. O amostrador foi mantido aberto durante 5 min na vazão gasosa amostrada, para purga antes de proceder à pré-concentração por SPME. O procedimento para pré-concentração foi: a agulha do suporte da fibra de SPME foi inserida no septo do amostrador e a fibra exposta por $20 \mathrm{~min}$. Em seguida, a fibra foi recolhida e imediatamente transferida para o injetor do GC-MS. As análises foram realizadas em cromatógrafo a gás Shimadzu, modelo GC-MS-QP2010 Plus, equipado com injetor split/splitless e detector por espectrometria de massas (MS), operando em modo EI a $70 \mathrm{eV}$ e modo Scan. As separações cromatográficas foram realizadas em coluna capilar RTX-5 (30 m x 0,25 mm x 0,25 $\mu \mathrm{m}$; Restek) usando hélio ultrapuro como gás carreador e auxiliar. A programação de temperatura do forno foi de $40{ }^{\circ} \mathrm{C}(5 \mathrm{~min}) ; 10{ }^{\circ} \mathrm{C} \mathrm{min}-1$ até $150{ }^{\circ} \mathrm{C}$ $(0 \mathrm{~min}) ; 20{ }^{\circ} \mathrm{C} \mathrm{min}^{-1}$ até $250{ }^{\circ} \mathrm{C}(2 \mathrm{~min})$. A temperatura do injetor foi fixada em $290{ }^{\circ} \mathrm{C}$ e a temperatura da interface GC-MS foi de $250{ }^{\circ} \mathrm{C}$. Os componentes presentes nas amostras foram identificados pela comparação de seus espectros de massa com dados da literatura (biblioteca NIST 05) ${ }^{15}$ e a percentagem de confiabilidade da identificação dos compostos foi maior ou igual a $96 \%$.

A avaliação da percentagem de conversão dos reagentes na produção de singás foi realizada na saída do reator, após o tratamento por plasma, usando duas técnicas diferentes: através de um analisador de gases (Kane May, KM9106EM Quintox) para a determinação de $\mathrm{O}_{2}, \mathrm{CO}, \mathrm{CO}_{2}, \mathrm{NO}, \mathrm{NO}_{2}$ e $\mathrm{NO}_{x}$, ou através de um cromatógrafo GCTCD (Cromacom, GC 35) para a determinação de $\mathrm{CH}_{4}$ e $\mathrm{CO}_{2}, \mathrm{H}_{2} \mathrm{e}$ CO. O cromatógrafo gasoso era equipado com duas colunas: peneira molecular 5A (1,8 m) para separação de $\mathrm{H}_{2}$ e CO e Poropak Q (1,8 m) empregada na separação $\mathrm{CH}_{4}$ e $\mathrm{CO}_{2}$. Foram empregadas as mesmas condições em ambas as colunas: argônio como gás de arraste $(25 \mathrm{~mL}$ $\min ^{-1}$ ); temperaturas do injetor, da coluna e do detector de 80, 60 e $200{ }^{\circ} \mathrm{C}$, respectivamente. A análise da porcentagem de conversão do $\mathrm{CH}_{4}$ e do $\mathrm{CO}_{2}$ foi feita por cromatografia a partir de amostras coletadas num amostrador de gases de $100 \mathrm{~mL}$. Os cromatogramas obtidos foram comparados com os obtidos a partir da mistura padrão $(60 \%$ $\mathrm{CH}_{4}, 40 \% \mathrm{CO}_{2}, 100 \mathrm{mg} \mathrm{L}^{-1}$ de $\mathrm{H}_{2} \mathrm{~S}$ ) e as porcentagens de conversão foram calculadas por comparação. A quantificação do $\mathrm{H}_{2}$ foi realizada a partir do respectivo padrão $(99,99 \%)$. 


\section{RESULTADOS E DISCUSSÃO}

\section{Análise dos gases antes e após o tratamento por plasma}

O perfil cromatográfico por GC-MS obtido das amostras gasosas utilizando a técnica de SPME é apresentado na Figura 2.

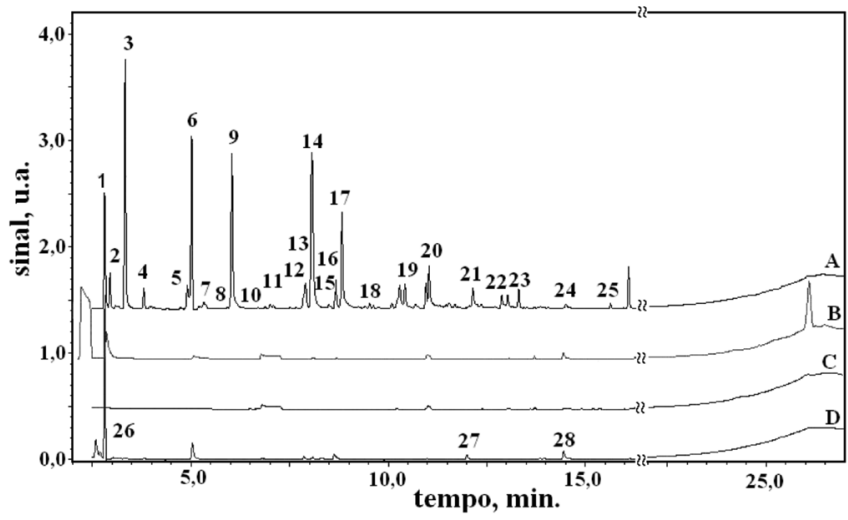

Figura 2. Perfil cromatográfico dos gases: A - impurezas de hidrocarbonetos e sulfetos contidas no metano; $B$ - plasma ligado somente com argônio; $C$ - análise do dióxido de carbono e D - análise dos gases produzidos após o tratamento por plasma. A identidade dos picos enumerados é mostrada nas Tabelas 1 e 2

O cromatograma da Figura 2 mostra em (A) as impurezas contidas no metano; (B) o branco com o plasma ligado somente com argônio; (C) a análise dos componentes contidos no dióxido de carbono e (D) a análise dos gases após o tratamento por plasma.

A Tabela 1 mostra a identidade dos picos enumerados no perfil cromatográfico da Figura 2A, referente à análise dos componentes gasosos contidos no metano comercial. Os compostos de número 21 e 23 da Tabela 1 foram os únicos identificados pertencentes à família dos organossulfurados.

O cromatograma da Figura 2D mostra que as espécies contidas no metano comercial tiveram sua concentração reduzida quase totalmente após o tratamento por plasma térmico, com exceção do benzeno, que teve um leve aumento na sua concentração.

A Tabela 2 apresenta os compostos produzidos pela descarga de plasma e identificados por SPME-GC-MS como sendo indeno $\left(\mathrm{C}_{9} \mathrm{H}_{8}\right)$, naftaleno $\left(\mathrm{C}_{10} \mathrm{H}_{8}\right)$ e benzeno $\left(\mathrm{C}_{6} \mathrm{H}_{6}\right)$ que foi identificado antes e depois do tratamento.

Os compostos policíclicos aromáticos (PAH's) são intermediários na formação do carbono sólido. ${ }^{16-19} \mathrm{O}$ mecanismo de produção destas espécies envolve duas etapas: a abstração de hidrogênio, que ativa as moléculas aromáticas e a adição de acetileno, que propaga o crescimento molecular. ${ }^{16}$ Foi demonstrado por Wang et al. ${ }^{17}$ que o mecanismo de abstração de hidrogênio $(\mathrm{H})$ e adição de acetileno $\left(\mathrm{C}_{2} \mathrm{H}_{2}\right)$, como mostrado no Esquema 1, é capaz de descrever quase quantitativamente os picos de concentração de PAH's. A identificação destes intermediários pela amostragem direta na fase gasosa ratifica a teoria de que o crescimento destas espécies se dá em fase gasosa. ${ }^{20}$

Experimentalmente foi possível observar que, com um pequeno excesso de metano em relação ao dióxido de carbono, houve pouca formação de carbono sólido, ratificando o mecanismo acima proposto (Esquema 1), através da formação do naftaleno como intermediário na nucleação do carbono.

Mais recentemente, foram propostos, por Shukla et al., ${ }^{19}$ outros mecanismos de formação de PHA's que contribuem com o mecanismo de abstração de hidrogênio e adição de acetileno. No presente trabalho identificou-se também o indeno (Tabela 2) cujo mecanismo de forma-
Tabela 1. Identificação do cromatograma da Figura 2. Impurezas de hidrocarbonetos e sulfetos contidas no metano

\begin{tabular}{|c|c|c|}
\hline Pico & Composto & Estrutura Molecular \\
\hline 1 & Benzeno & \\
\hline 2 & 3-metil-hexano & \\
\hline 3 & Heptano & \\
\hline 4 & Metil-cicloexano & \\
\hline 5 & 2 metil-heptano & \\
\hline 6 & Tolueno & \\
\hline 7 & Cis-1, 3-dimetil-cicloexano & \\
\hline 8 & $\begin{array}{l}\text { trans-1, 3-dimetil-ciclo- } \\
\text { exano }\end{array}$ & \\
\hline 9 & Octano & \\
\hline 10 & 3,3,4 trimetil-hexano & \\
\hline 11 & 2 metil-decano & \\
\hline 12 & Etil-ciclohexano & \\
\hline 13 & 2-metil-octano & \\
\hline 14 & 1,3 dimetil-benzeno & \\
\hline 15 & 1-etil-4-metilciclohexano & \\
\hline 16 & 1,2 dimetil-benzeno & \\
\hline 17 & Nonano & \\
\hline 18 & Propil-ciclohexano & \\
\hline 19 & 1,2,3-trimetil-benzeno & \\
\hline 20 & Decano & \\
\hline 21 & $\begin{array}{l}\text { Dissulfeto de } 1 \text {-(metil-etil), } \\
\text { (1,1 dimetiletil) }\end{array}$ & \\
\hline 22 & Undecano & \\
\hline 23 & Dissulfeto de di-tert-butila & \\
\hline 24 & Dodecano & \\
\hline 25 & Tridecano & \\
\hline
\end{tabular}


Tabela 2. Identificação do cromatograma da Figura 2. Intermediários produzidos na reforma do biogás por plasma térmico

\begin{tabular}{ccc}
\hline Pico & Intermediário & Estrutura Molecular \\
\hline 26 & Benzeno & Naftaleno \\
28 & Indeno &
\end{tabular}

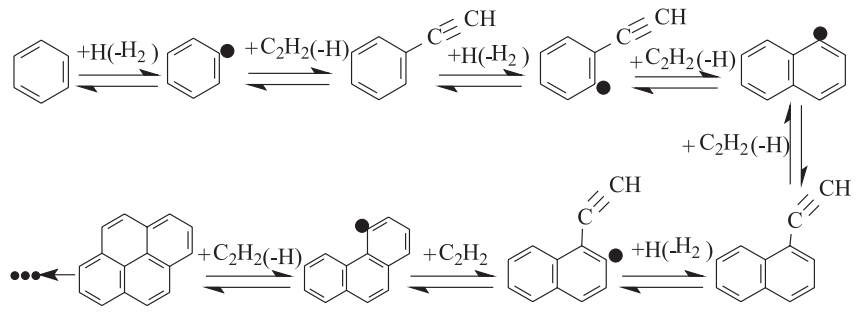

Esquema 1. Mecanismo de abstração de hidrogênio e adição de acetileno para formação e crescimento de compostos policíclicos aromáticos

ção provável (Equação 7) é pela adição do acetileno ao radical benzil, seguido pela eliminação de hidrogênio atômico e posterior ciclização.

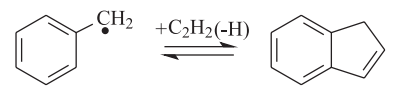

O monóxido de carbono (CO) foi o único produto oxigenado identificado por GC-TCD. Nas análises por GC-MS, nenhum outro composto oxigenado foi identificado, indicando alta seletividade na produção de $\mathrm{CO}$ no processo. Na reforma do metano por plasma frio de descarga de barreira dielétrica $\mathrm{DBD}$, foram identificados diferentes produtos oxigenados, como ${ }^{21} \mathrm{CH}_{3} \mathrm{OH}, \mathrm{CH}_{3} \mathrm{OCH}_{3}$ e $\mathrm{C}_{2} \mathrm{H}_{5} \mathrm{OH}$ e vários hidrocarbonetos; $; 2 \mathrm{C}_{2} \mathrm{H}_{2}, \mathrm{C}_{2} \mathrm{H}_{4}, \mathrm{C}_{2} \mathrm{H}_{6}, \mathrm{C}_{3} \mathrm{H}_{6}, \mathrm{C}_{3} \mathrm{H}_{8}, \mathrm{C}_{4} \mathrm{H}_{8}, n-\mathrm{C}_{4} \mathrm{H}_{10}$, $i-\mathrm{C}_{4} \mathrm{H}_{10}$ e $\mathrm{CH}_{3} \mathrm{OH}$. Estes compostos não foram identificados neste trabalho, indicando um mecanismo de reação mais eficiente para a reforma do biogás por plasma térmico.

A tecnologia de plasma térmico oferece vantagens em relação aos outros tipos de descargas elétricas, tais como, alta conversão de reagentes e altos rendimentos dos produtos em elevadas vazões gasosas, podendo, portanto, ser aprimorada para aplicação industrial. ${ }^{12}$

\section{Efeito da concentração de metano}

A Figura 3 mostra a conversão dos reagentes em função da concentração de metano injetado (4 a 12\%) mantendo-se constante a concentração de dióxido de carbono em 7,0\%. Nota-se que a conversão de $\mathrm{CO}_{2}$ diminui com o aumento de $\mathrm{CH}_{4}$ injetado, enquanto a conversão do metano diminuiu somente a partir de $9 \%$ de $\mathrm{CH}_{4}$ inicial. As reações que ocorrem nestas condições são majoritariamente a reação 1 , reforma a seco do biogás, e a reação 4 , em que o dióxido de carbono reage com o hidrogênio do meio reacional, produzindo água e monóxido de carbono. A partir desta concentração começa também a formação de carbono sólido atribuída à reação de decomposição do metano (Equação 6) em ausência de oxigênio. A reação 6 mostra que a estequiometria da reação de formação do gás de síntese é proporcional, 1:1, o excesso de metano no meio leva à produção de carbono sólido tipo fuligem.

A diminuição da conversão dos reagentes com o aumento da concentração total dos gases no sistema $\left(\mathrm{CO}_{2}+\mathrm{CH}_{4}\right)$ se deve à di-

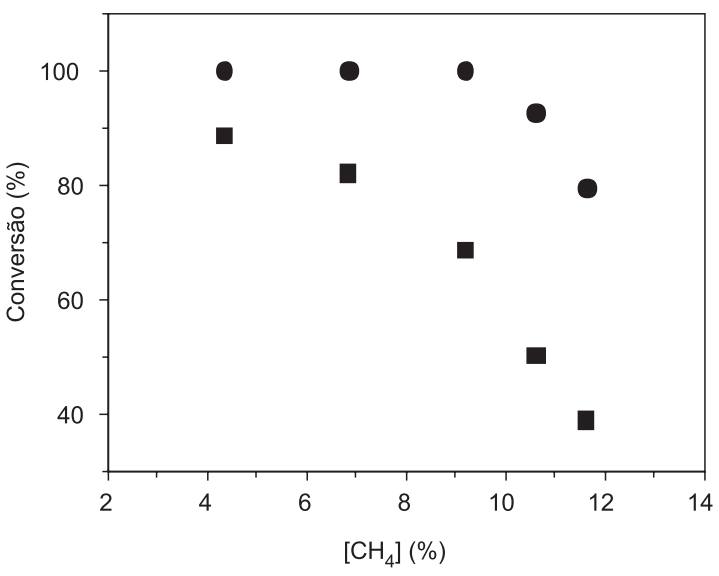

Figura 3. Efeito da concentração de metano na conversão do metano e dióxido de carbono $\left(\left[\mathrm{CO}_{2}\right]_{\text {inicial }}=7,0 \%\right)$. $\left[\mathrm{CO}_{2}\right] ; \bullet\left[\mathrm{CH}_{4}\right]$

minuição da energia disponível, por mol de reagentes, uma vez que a potência aplicada na tocha é constante. Como a energia de ativação é uma propriedade extensiva, que depende do balanço de massa do sistema, quanto maior a massa maior a energia requerida no processo.

A Figura 3 também mostra que a conversão tanto do metano bem como do dióxido de carbono é favorecida em concentrações baixas de metano. Este comportamento é diferente do observado na reação de reforma empregando-se catalisadores. Em um sistema catalítico convencional, utilizando-se níquel suportado, por exemplo, a conversão de $\mathrm{CH}_{4}$ aumenta com a diminuição da concentração de metano, enquanto a conversão de $\mathrm{CO}_{2}$ diminui, concordando com os cálculos termodinâmicos..$^{23,24}$ Neste trabalho o resultado experimental obtido com plasma térmico na reação de reforma não segue os mesmos padrões termodinâmicos, mostrando o caráter de não equilíbrio da ativação por plasma ou dissociação por impacto de elétrons. ${ }^{24}$

Na reação de reforma do biogás por plasma térmico, a alta temperatura do meio e todas as espécies químicas existentes no plasma participam na quebra das ligações químicas para produzir novas espécies, sendo difícil de predizer teoricamente a energia envolvida na formação dos produtos finais da reação. Portanto, as contribuições da área de química do plasma são, em sua maioria, fundamentadas em dados experimentais. ${ }^{25}$

\section{Efeito da concentração do dióxido de carbono}

A Figura 4 mostra a porcentagem de conversão em função da concentração de $\mathrm{CO}_{2}$ injetado, mantendo-se constante a concentração de metano (8\%). A conversão de ambos os reagentes aumenta com o aumento da concentração de $\mathrm{CO}_{2}$ no intervalo de 3,2 a 10,1\%, quando atinge seu valor máximo de conversão. $\mathrm{O}$ aumento da conversão de ambos os reagentes $\left(\mathrm{CO}_{2}\right.$ e $\left.\mathrm{CH}_{4}\right)$ deve-se ao deslocamento do equilíbrio da reação 1 para a direita devido à produção de $\mathrm{CO}$ a partir do oxigênio proveniente da quebra do $\mathrm{CO}_{2}$ e do carbono proveniente da quebra do $\mathrm{CH}_{4}$. A reação de formação de $\mathrm{CO}$ e $2 \mathrm{H}_{2}$ a partir de $\mathrm{CH}_{4}$ em presença de oxigênio é favorecida liberando $-38 \mathrm{~kJ} \mathrm{~mol}^{-1}$.

Em concentrações de $\mathrm{CO}_{2}$ mais elevadas a conversão dos reagentes decresce e inicia-se a produção de carbono sólido tipo fuligem. A produção de fuligem pode ser explicada através da reação de Boudouard (Equação 5) em que ocorre uma diminuição da conversão de $\mathrm{CO}_{2}$ e do rendimento de $\mathrm{CO}$, devido ao excesso de $\mathrm{CO}$ produzido pela reação de reforma do biogás (Equação 1). Quando a concentração de $\mathrm{CO}$ produzido na reforma é maior do que a requerida para manter o equilíbrio estequiométrico das reações, a produção de carbono sólido aumenta no meio. Conforme demonstrado por Khalaf et al., ${ }^{11}$ para a degradação de tetracloreto de carbono $\left(\mathrm{CCl}_{4}\right)$ por plasma térmico, 


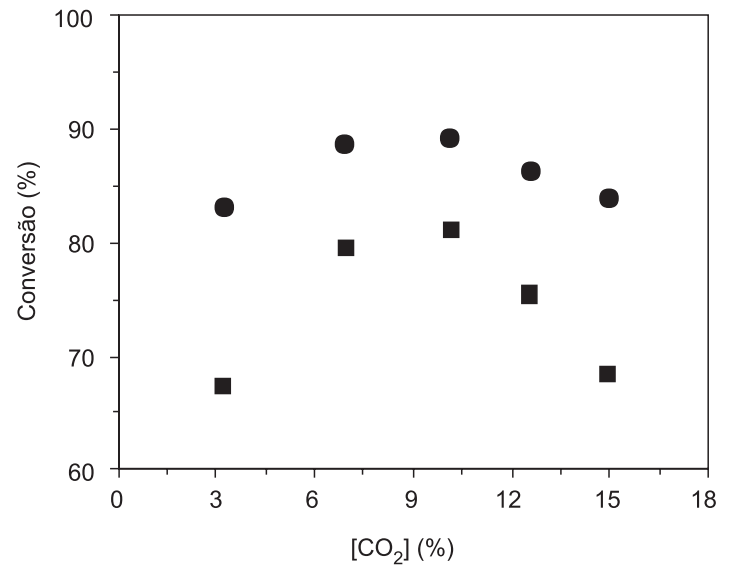

Figura 4. Efeito da concentração de $\mathrm{CO}_{2}$ na conversão do metano e dióxido de carbono $\left(\left[\mathrm{CH}_{4}\right]_{\text {inicial }}=8 \%\right)$. $\left[\mathrm{CO}_{2}\right] ; \bigcirc\left[\mathrm{CH}_{4}\right]$

com o aumento do fluxo do gás plasmogênico (argônio) mantendo constantes a vazão de $\mathrm{CCl}_{4}$ e a potência aplicada ao plasma a eficiência de degradação diminui. Isto ocorre devido à redução do tempo de residência da amostra no interior do reator próximo ao jato de plasma, região de alta temperatura. A Figura 4 mostra que quanto maior a porcentagem de $\mathrm{CO}_{2}$, maior a diluição da amostra dentro do reator, reduzindo a eficiência do processo.

Rueangjit et al..$^{24}$ investigaram a reforma do biogás por gliding arc e mostraram que o dióxido de carbono presente no meio aumentou a conversão de metano, reduziu a quantidade de carbono sólido gerado e diminuiu o consumo da energia específica. Yang et al..$^{26} \mathrm{empregaram}$ descarga tipo agulha na reforma do biogás e também observaram que a formação de carbono depende fortemente da composição dos gases injetados. No presente trabalho os dados experimentais mostraram que o excesso de $\mathrm{CO}_{2}$ aumenta a conversão de metano e reduz a quantidade de carbono sólido gerado, sendo a relação de aproximadamente $\left[\mathrm{CO}_{2}\right] /$ $\left[\mathrm{CH}_{4}\right]=1,3$ a melhor encontrada para o processo.

A conversão do metano foi superior à conversão do dióxido de carbono nos resultados obtidos neste trabalho. Resultados semelhantes foram encontrados por Goujard et al. ${ }^{21}$ indicando que a conversão do metano é favorecida no processo devido à alta temperatura do plasma, considerando que a entalpia padrão de formação do metano é $\Delta \mathrm{H}^{\circ}-74,8 \mathrm{~kJ} \mathrm{~mol}^{-1}$ e do $\mathrm{CO}_{2}$ é $\Delta \mathrm{H}^{\circ}-393 \mathrm{~kJ} \mathrm{~mol}^{-1}$.

\section{CONCLUSÃO}

As impurezas de hidrocarbonetos contidas na mistura gasosa comercial sofreram degradação durante o processo de reforma por plasma térmico. Os resultados obtidos sugerem que o plasma térmico é uma ferramenta poderosa a ser explorada na reforma do biogás, não necessitando do emprego de catalisadores e nem de pré-tratamento dos gases para remoção de compostos de enxofre, reduzindo custos operacionais e simplificando o processo.

Os dados experimentais mostraram que o excesso de $\mathrm{CO}_{2}$ aumenta a conversão de metano e reduz a quantidade de carbono sólido gerado, sendo a proporção $\left[\mathrm{CO}_{2}\right] /\left[\mathrm{CH}_{4}\right]=1,3$ a melhor relação encontrada para o processo. Em proporções menores de 1,3, que no processo favorecem a produção de carbono sólido, foram identificados benzeno $\left(\mathrm{C}_{6} \mathrm{H}_{6}\right)$, indeno $\left(\mathrm{C}_{9} \mathrm{H}_{8}\right)$ e naftaleno $\left(\mathrm{C}_{10} \mathrm{H}_{8}\right)$ que são conhecidamente subprodutos precursores da formação do carbono sólido tipo fuligem. Nenhum composto oxigenado foi identificado além do monóxido de carbono, indicando alta seletividade na produção de $\mathrm{CO}$.

\section{AGRADECIMENTOS}

À CAPES pela bolsa concedida a P. I. Khalaf; ao INCT de Catálise em Sistemas Moleculares Nanoestruturados; à empresa Carbonobrasil pelo apoio financeiro concedido.

\section{REFERÊNCIAS}

1. Rasi, S.; Veijanen, A.; Rintala, J.; Energy 2007, 32, 1375.

2. Atkins, P.; de Paula, J.; Atkins' Physical Chemistry, $9^{\text {th }}$ ed., Oxford University Press: Oxford, 2010.

3. Juan-Juan, J.; Roman-Martınez, M. C.; Illan-Gomez, M. J.; Appl. Catal., A 2006, 301, 9 .

4. Luna, A. E. C.; Iriarte, M. E.; Appl. Catal., A 2008, 343, 10.

5. Huang, C. P.; T-Raissi, A.; J. Power Sources 2007, 163, 645.

6. Bromberg, L.; Cohn, D. R.; Rabinovich, A.; O'Brien, C.; Hochgreb, S.; Energy Fuels 1998, 12, 11.

7. Bromberg, L.; Cohn, D. R.; Rabinovich, A.; Int. J. Hydrogen Energy 1997, 22, 83.

8. Blomen, L.; Mugerwa, M. N.; Fuel Cell Systems, Plenum Press: New York, 1993.

9. Friedman, A.; Plasma Chemistry, Cambridge University Press: New York, 2008.

10. De Souza, I. G.; Debacher, N. A.; PI 0700517, 2008.

11. Khalaf, P. I.; de Souza, I. G.; Carasek, E.; Debacher, N. A.; Quim. Nova 2010, 33, 398 .

12. Tao, X.; Bai, M.; Wu, Q.; Huang, Z.; Yin, Y.; Daí, X.; Int. J. Hydrogen Energy 2009, 34, 9373; Yan, B. H.; Wang, Q.; Jin, Y.; Chen, Y.; Plasma Chem. Plasma Process. 2010, 30, 257.

13. Khalaf, P. I.; Tese de Doutorado, Universidade Federal de Santa Catarina, Brasil, 2009.

14. Cubas, A. L. V.; Souza, I. G.; Debacher, N. A.; J. Braz. Chem. Soc. 2005, $16,531$.

15. Linstrom, P.; Mirokhin, Y.; Tchekhovskoi, D.; The NIST 05 Mass Spectral Library (NIST/EPA/NIH), National Institute of Standards and Technology, USA, 2005.

16. Wang, H.; Frenklach, M.; J. Phys. Chem. 1994, 98, 11465.

17. Wang, H.; Frenklach, M.; Combust. Flame 1997, 110, 173.

18. Appel, J.; Bockhorn, H.; Frenklach, M.; Combust. Flame 2000, 121, 122.

19. Shukla, B; Susa, A.; Miyoshi, A.; Koshi, M.; J. Phys. Chem. A 2008, 112,2362

20. Richter, H.; Howard, J. B.; Prog. Energ. Comb. Sci. 2000, 26, 565.

21. Goujard, V.; Tatibouet, J. M.; Batiot-Dupeyrat, C.; Appl. Catal., A 2009, $353,228$.

22. Jiang, T.; Li, Y.; Liu, C.; Xu, G.; Eliasson, B.; Xue, B.; Catal. Today 2002, 72, 229

23. Pietruszka, B.; Heintze, M.; Catal. Today 2004, 90, 151.

24. Rueangjitt, N.; Sreethawong, T.; Chavadej, S.; Plasma Chem. Plasma Process. 2008, 28, 49.

25. Petitpas, G.; Rollier, J. D.; Darmon, A.; Gonzales-Aguilar, J.; Metkemeijer, R.; Int. J. Hydrogen Energy 2007, 32, 2848.

26. Yang, Y.; Ind. Eng. Chem. Res. 2002, 41, 5918. 